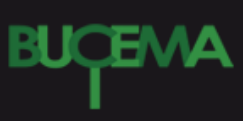

Bulletin du centre d'études médiévales d'Auxerre | BUCEMA

Hors-série $n^{\circ} 3$ | 2010

Présentation et mise en valeur des sites archéologiques religieux en milieu urbain

\title{
Une archéologie responsable
}

\section{Christian Sapin}

\section{(2) OpenEdition}

1 Journals

\section{Édition électronique}

URL : https://journals.openedition.org/cem/11342

DOI : $10.4000 /$ cem. 11342

ISSN : 1954-3093

Éditeur

Centre d'études médiévales Saint-Germain d'Auxerre

Référence électronique

Christian Sapin, «Une archéologie responsable », Bulletin du centre d'études médiévales d'Auxerre | BUCEMA [En ligne], Hors-série n 3 | 2010, mis en ligne le 19 février 2010, consulté le 03 mars 2023. URL : http://journals.openedition.org/cem/11342; DOI : https://doi.org/10.4000/cem.11342

Ce document a été généré automatiquement le 3 mars 2023

\section{(c) (i) (2)(2)}

Creative Commons - Attribution - Pas d'Utilisation Commerciale - Partage dans les Mêmes Conditions 4.0 International - CC BY-NC-SA 4.0

https://creativecommons.org/licenses/by-nc-sa/4.0/ 


\title{
Une archéologie responsable
}

\author{
Christian Sapin
}

À lla suite de plusieurs découvertes en milieu urbain, ces vingt dernières années, de nouveaux sites religieux connus par les sources, comme celui de Luxeuil ou ignorés de celles-ci comme la basilique funéraire de la Rue Maraval à Marseille, nous avons souhaité avec Sébastien Bully, réfléchir à partir d'études de cas, sur les choix qui ont pu être faits ou qui peuvent être faits pour conserver in situ des témoignages souvent rares si ce n'est exceptionnels.

Nous sommes loin de l'époque où l'archéologue faisait là où cela l'enchantait ses « trous » pour justifier sa curiosité et repartait l'âme tranquille, riche d'un nouveau savoir qu'il transmettait à ses confrères ou à quelques érudits. Avec la professionnalisation, ce métier a évolué. Nous sommes dans une période de responsabilité. C'est la nature même de notre intervention qui a changé, responsable scientifique d'une Histoire comme responsable -citoyen, redevable des deniers publics.

C'est avec la connaissance que nous avançons et osons affronter l'avenir ; c'est avec la conservation visible de certaines données que nous comprenons les acquis. Que dirions-nous des élévations du haut Moyen Âge sans cette conservation et ce sauvetage du baptistère de Poitiers à la fin du XIX ${ }^{\mathrm{e}}$ siècle? Que saurions-nous précisément des surfaces de stucs sans l'intervention de Mérimée à Grenoble ? Comment comprendre le fonctionnement de la cathédrale de Saint-Jean de Maurienne sans sa crypte retrouvée et présentée? Garder in situ avec des élévations reste un problème complexe où intervient également la question des restaurations et de leur déontologie depuis la Charte de Venise.

Avec le recul, on réalise qu'il s'agit de témoins indispensables à cette bibliothèque de sites dont parlait Charles Bonnet en 1999; une bibliothèque interrogeable à tout moment. Ce sont de nouvelles archives dont la conservation est exigeante et que l'on ne peut exhumer et garder au jour sans se soucier de leur avenir. Il suffit pour s'en convaincre de regarder le devenir cinquante après des cryptes archéologiques de Limoges ou de Saint-Denis. On pourrait citer l'état dégradé des structures métalliques de Saint-Paul de Narbonne comme l'attente de protection définitive sur le Clos de la Lombarde. Enterrer / ne pas enterrer ; exposer / présenter... 
Depuis 20 ans, de nombreuses solutions ont été envisagées ou adoptées ; il nous faut en examiner certaines pour apprécier les choix qui ont été faits, les méthodes utilisées, les résultats quelques années après, auprès du public comme auprès des scientifiques, et les limites quelques fois atteintes par ces présentations maintenant datées.

Cess exemples touchent ainsi à la fois l'intérêt scientifique qui a pu justifier les choix de non rebouchage et de conservation in situ, mais également sont abordées bien d'autres questions : comme la résolution des contraintes propres à des sites urbains densément occupés, les processus qui ont permis ou n'ont pas permis l'aboutissement du projet, les différents acteurs de l'entreprise, les moyens divers de sensibilisation in situ ou d'accompagnement, images, textes, maquette, virtuel ; le rôle de la signalisation, les sources d'inspiration... enfin les problèmes de maintenance, de suivi, de survie quelques années après.

En arrière-plan demeure la variété selon les régions et les pays des rapports cultuel / culturels, aujourd'hui, facteur de curiosité, de découverte ou de rejet. On perçoit très bien que les choix correspondent souvent à des moments donnés de notre histoire, à des acteurs donnés et qu'aujourd'hui plus qu'hier chacun de nous s'interroge sur le devenir des sites religieux. Les choix de conservation sont ainsi économiques (coûts et profits ${ }^{1}$ ), politiques (tourisme), avant d'être scientifiques. À nous d'en démontrer l'intérêt pour la société du $\mathrm{XXI}^{\mathrm{e}}$ siècle. Ce sont toujours des paris pour l'avenir surtout dans ces milieux urbains chaque jour grandissant, alors que jamais dans nos civilisation les changements n'ont été aussi rapides en bouleversant comme jamais les repères. Ce sont des paris pour des médiations qui ne soient pas que virtuelles. Quelle réalité matérielle de nos connaissances souhaitons-nous, en effet, transmettre, ceci à un moment où nous savons que nos connaissances emmagasinées par l'informatique sont toujours menacées de disparition à court ou long terme?

" E'être humain a un besoin fondamental de mémoire. Il construit celle-ci en se référant, en particulier, à des lieux et à des objets» déclare l'art.1. Des principes édictés par la commission Suisse "Pour la conservation du patrimoine culturel bâti ». La découverte de vestiges ici et là sont peut être, par le souci que l'on peut avoir de leur conservation/ présentation, une chance pour donner cette foi en l'avenir qui nous manque!

\section{NOTES}

Sur cette question et le rapport au public face aux restitutions cf. Conclusion de Michel Colardelle "Pour une éthique de la restitution sur les sites archéologiques », in De la restitution en Archéologie, Actes du Colloque d'Ensérune (octobre 2005), Collection Idées et Débats, Ed. du Patrimoine, Centre des Monuments Nationaux, Paris, 2008, p. 285-293

[http://editions.monuments-nationaux.fr/fr/les-ouvrages-en-ligne/bdd/chapitre/39/LGBOOK/ fr].

1. Sur cette question et le rapport au public face aux restitutions cf. Conclusion de Michel Colardelle « Pour une éthique de la restitution sur les sites archéologiques », in De la restitution en 
Archéologie, Actes du Colloque d'Ensérune (octobre 2005), Collection Idées et Débats, Ed. du Patrimoine, Centre des Monuments Nationaux, Paris, 2008, p. 285-293

[http://editions.monuments-nationaux.fr/fr/les-ouvrages-en-ligne/bdd/chapitre/39/LGBOOK/

fr].

INDEX

Mots-clés : ville

Index géographique : Europe 